•生物编目・

\title{
采自西藏和新疆的7种中国新记录植物
}

\author{
扈凡斌(101,2,3，辛玥 ${ }^{1,2,3}$, 郭柯 ${ }^{4}$, 赵利清 $1,2,3^{*}$
}

1. 内蒙古大学生态与环境学院, 呼和浩特 010021; 2. 蒙古高原生态与资源利用教育部重点实验室, 呼和浩特 010021; 3. 草原生态安全教 育部协同创新中心，呼和浩特 010021; 4. 中国科学院大学, 北京 100049

摘要: 本文报道了 6 个中国被子植物新记录种及1个新记录亚种, 分别是采自西藏的灰滨藜(Atriplex pallida)、类球花藜(Blitum litwinowii)、滨藜状藜(Chenopodium atripliciforme)、土耳其针茅(Stipa turkestanica)、扁果岩蓼(Polygonum cognatum subsp. chitralicum)及新疆的宝格达黄芪(Astragalus baitagensis)和神香草叶千屈菜(Lythrum hyssopifolia), 观察了部分类群的微形态 特征并提供了生境或形态图。凭证标本均存放于内蒙古大学植物标本馆(HIMC)。

关键词: 被子植物; 苋科; 藜科; 新分布

扈凡斌, 辛玥, 郭柯, 赵利清 (2021) 采自西藏和新疆的7种中国新记录植物. 生物多样性, 29, 1265-1270. doi: 10.17520/biods.2021181. Hu FB, Xin Y, Guo K, Zhao LQ (2021) Seven newly recorded species from Xizang and Xinjiang in China. Biodiversity Science, 29, 1265-1270. doi: 10.17520/biods.2021181.

\section{Seven newly recorded species from Xizang and Xinjiang in China}

Fanbin $\mathrm{Hu}^{1,2,3}$, Yue $\mathrm{Xin}^{1,2,3}$, Ke Guo ${ }^{4}$, Liqing Zhao ${ }^{1,2,3^{*}}$

1 School of Ecology and Environment, Inner Mongolia University, Hohhot 010021

2 Key Laboratory of Ecology and Resource Use of the Mongolian Plateau, Ministry of Education, Hohhot 010021

3 Collaborative Innovation Center for Grassland Ecological Security, Ministry of Education, Hohhot 010021

4 University of Chinese Academy of Sciences, Beijing 100049

\section{ABSTRACT}

Aim: We aim to understand the plant diversity in the border areas of Xizang and Xinjiang. These border areas are the focus and hot spots of biodiversity conservation.

Method: In this study, plants were collected and photographed through field investigation, made into specimens, and sorted out and identified. The voucher specimens for each reported species were preserved in the Herbarium of Inner Mongolia University (HIMC).

Results: Six newly recorded angiosperm species and one sub-species in China were reported, of which Atriplex pallida, Blitum litwinowii, Chenopodium atripliciforme, Stipa turkestanica and Polygonum cognatum subsp. chitralicum were found in the Xizang Autonomous Region, while Astragalus baitagensis and Lythrum hyssopifolia were collected from the Xinjiang Uygur Autonomous Region.

Conclusion: The investigation of plants in the border areas of Xizang and Xinjiang with neighboring countries is relatively weak, and should be further strengthened in the investigation of flora and resources in the future. The discovery of new distributed plants is of great significance to the nature of the local flora and the attribution of the regionalization.

Key words: angiosperm; Amaranthaceae; Chenopodiaceae; new distribution

中国地域辽阔、山川纵横, 地跨北半球的寒温 带、温带、暖温带、亚热带和热带, 是植物多样性 最丰富的国家之一(Sang et al, 2011)。根据Flora of
China记载，中国共有维管植物31,362种(Wu et al, 2013), 而且随着研究人员的不断调查, 中国维管植 物数量仍以每年 200 个物种的规模在增长(Du et al,

收稿日期: 2021-05-08; 接受日期: 2021-06-25

基金项目：第二次青藏高原综合科学考察研究(2019QZKK0301)

* 通讯作者 Author for correspondence. E-mail: E-mail: zhaotieniu@126.com 
2020)。2013-2018年间, 我们在新疆、西藏等地进 行了多次植被和植物区系调查。在室内标本鉴定过 程中, 通过查阅 《中国植物志》(孔宪武和朱格麟, 1979; 李树刚和刘兰芳，1983; 孙永华和郭本兆， 1987; 傅坤俊等, 1993; 李安仁，1998)、Flora of China (Li \& Bao, 2003; Zhu, 2003a, b; Wu, 2006; Qin, 2007; Xu, 2010)、 《新疆植物志》(新疆植物志编辑 委员会, 2011)、《西藏植物志》(吴征镒, 1983, 1987) 及相邻国家和地区的植物志、检索表(Nasir \& Ali, 1979; Grubov, 2001, 2007; Grubov \& Ulzijchutag, 2004), 以及相关植物分类学文献(Sukhorukov \& Kushunina, 2015; Sukhorukov et al, 2019), 我们发现 了 6 个中国新记录种和 1 个中国新记录亚种, 分别为 宝格达黄芪(Astragalus baitagensis)、灰滨藜(Atriplex pallida)、类球花藜(Blitum litwinowii)、滨䓠状葱 (Chenopodium atripliciforme)、神香草叶千屈菜 (Lythrum hyssopifolia) 、土耳其针茅 (Stipa turkestanica)和扁果岩苶(Polygonum cognatum subsp. chitralicum), 现予以报道。本文新记录物种的鉴定 及描述依据最新的分类学处理, 物种按照学名字母 顺序进行排序, 凭证标本均存放于内蒙古大学植物 标本馆(HIMC)。

\section{中国新记录}

(1)宝格达黄芪(豆科Leguminosae; 黄芪属Astragalus)

Astragalus baitagensis Sancz. ex N. Ulziykh. in Byull. Moskovsk. Obshch. Isp. Prir. Otd. Biol. n.s., 95(1): 109 (1990).

分布: 蒙古国西部的石质山坡, 在新疆的分布 为中国新记录。宝格达黄芪在国外的分布与中国新 记录地位于准噶尔荒漠北塔格宝格达山, 该山地是 中国和蒙古国的界山。

凭证标本: 赵利清、旭日、要振宇, XJ16-8022 (HIMC), 2016-8-3, 新疆奇台县北塔山牧场北塔山, 石质山坡灌丛, $45^{\circ} 17^{\prime} \mathrm{N}, 90^{\circ} 39^{\prime} \mathrm{E}$, 海拔2,441 m。

种地理成分：准噶尔戈壁(北塔山)分布种。

分类学备注: 蒙古国植物检索表中记载该种小 叶正面无毛(Grubov, 2001), 我们所采集标本小叶 正面被稀疏的白色单毛而与原描述稍有差别。

宝格达黄芪学名种加词是以产地北塔格宝格 达山命名的。另外, 在黄芪属中还有一种以北塔山 为种加词命名的物种, 即北塔山黄芪 (A. beitashanensis), 为了避免重复, 我们选用了宝格达 黄芪为该新分布种的中文名，“宝格达”是蒙古语的 音译，其汉语意思为“神山”。这两种黄芪其实差别 很大，宝格达黄芪属于黄芪亚属(Astragalus Subgen. Phaca), 叶被单毛，花葶在花期后不膨大(图1); 北 塔山黄芪属于胀颌亚属 (Astragalus Subgen. Calycocystis), 叶被丁字毛, 花墓在花期后即开始膨 大呈膀胱状, 并包被荚果(Chai \& Yan, 2010)。

\section{(2)灰滨僽(苋科Amaranthaceae; 滨僽属Atriplex)}

Atriplex pallida (Moq.) Sukhor. in Phytotaxa 226: 288 (2015); Chenopodium pallidum Moq. in Chenop. Monogr. Enum.: 30 (1840); Atriplex schugnanica Iljin in Fl. URSS 6: 97 (1936).

分布: 中亚、帕米尔高原、兴都库什山脉、喀 喇昆仑南部、喜马拉雅西部的多石多沙地, 在西藏 的分布为中国新记录。灰滨愁新记录地西藏札达县 底雅乡与巴基斯坦东部、印度北部的分布同属于喜 马拉雅西部, 在国内相似生境中有该种分布。

凭证标本：赵利清，XZ18-8008 (HIMC), 2018-9-2, 西藏札达县底雅乡象泉河河谷, 路边; 赵 利清, XZ18-8009 (HIMC), 2018-9-2, 西藏札达县底

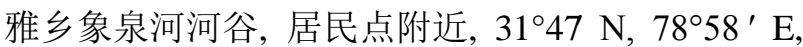
海拔3,627 m。

种地理成分：中亚分布种。

Flora of China 中在记载鞑靼滨愁 (Atriplex tatarica) 时指出, “Atriplex schugnanica (灰滨藜 Atriplex pallida的异名)分布于帕米尔山和中亚东部 (亚州中部), Grubov在1966年报道中国新疆西部和 北部(莎车县靠近叶尔差河附近)有该物种分布”，但 可能著者未见到可靠的标本，故未在志书中正式收 录(Zhu, 2003b)。最新文献资料记载该物种很可能在 中国西藏西部有分布(Sukhorukov et al, 2019)。我们 2018年在西藏札达县采集的标本证实了中国西藏 西部有该植物分布，但未在新疆采集到该植物，国 内也未见到相关记载报道，故该种在新疆的分布仍 需深入调查研究。

灰滨藜与鞑靼滨藜形态接近。主要区别在于灰 滨䔉叶正面无毛, 茎生叶近全缘, 叶柄长 $15 \mathrm{~mm}$ 以 上; 鞑靼滨藜叶正面具硬毛，茎生叶多浅裂至中裂， 叶柄长 $10 \mathrm{~mm}$ 以下(图2)。

(3)类球花萩(苋科Amaranthaceae; 球花藜属Blitum)

Blitum litwinowii (Paulsen) S. Fuentes, Uotila et 


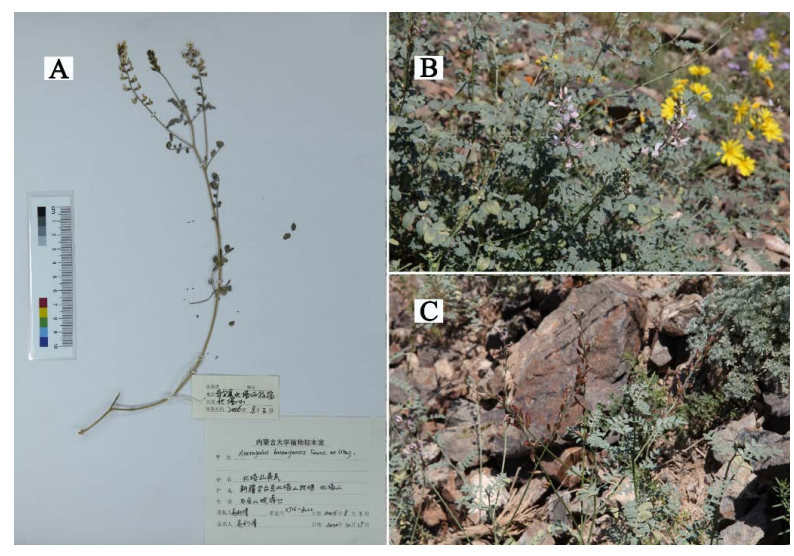

图1 宝格达黄芪的标本(A)和植株(B、C)

Fig. 1 Specimen (A) and plants (B, C) of Astragalus baitagensis

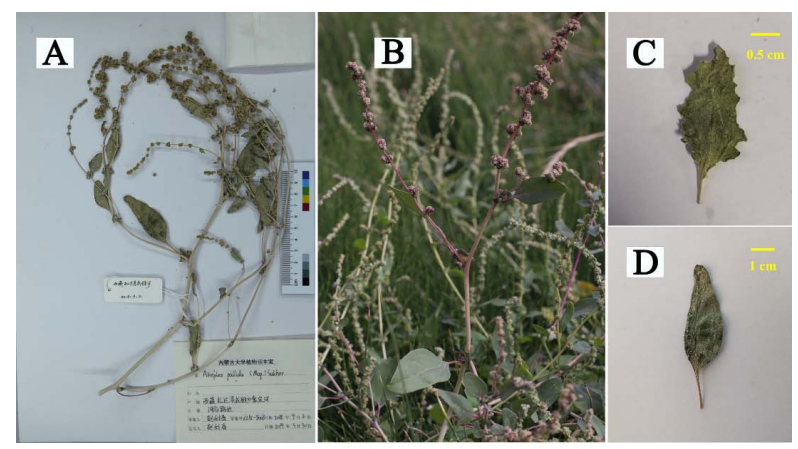

图2 灰滨藜的标本(A)、䅦朱 (B)和叶(D)及鞑靼滨藜的叶(C) Fig. 2 Specimen (A), plant (B), leaf (D) of Atriplex pallida and leaf (C) of A. tatarica

Borsch in Willdenowia 42: 17 (2012); Monolepis litwinowii Paulsen in Vidensk. Meddel. Dansk Naturhist. Foren. Kjøbenhavn 6(5): 187 (1903); Chenopodium litwinowii (Paulsen) Uotila in Ann. Bot. Fenn. 30: 190 (1993).

分布: 兴都库什山脉、帕米尔高原、喀喇昆仑 山脉的山地草原, 在西藏的分布为中国新记录。类 球花藜新记录地西藏札达县底雅乡与巴基斯坦北 部、印度北部的分布同属于喜马拉雅西部, 在国内 相似生境中有该种分布。

凭证标本: 赵利清、郭柯, XZ13-038 (HIMC), 2013-9-3, 西藏札达县底雅乡, 路边, 31 ${ }^{\circ} 50^{\prime} \mathrm{N}$, $79^{\circ} 00^{\prime} \mathrm{E}$, 海拔 $4,373 \mathrm{~m}$ 。

种地理成分: 西喜马拉雅分布种。

球花藜属(Blitum)植物在 Flora of China 等植物 志中仍归属于藜属(Chenopodium) (Zhu, 2003a), 基 于系统发育学以及形态学, Fuentes-Bazan 等(2012) 支持球花萩属的成立, 并将 Chenopodium litwinowii

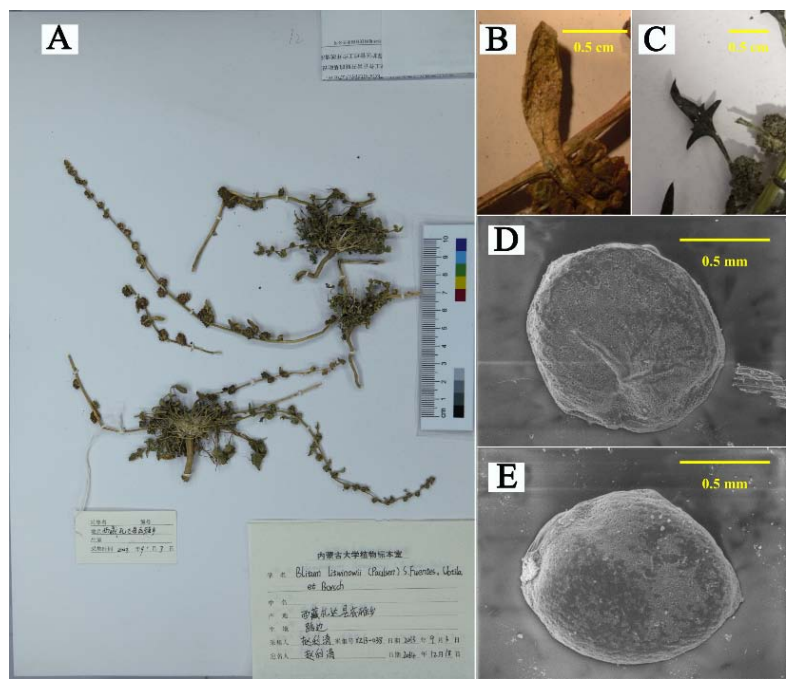

图3 类球花藜的标本 $(\mathrm{A})$ 、苞片 $(\mathrm{B})$ 、种子 $(\mathrm{E})$ 与球花藜的苍 片(C)、种子(D)

Fig. 3 Specimen (A), bract (B), seed (E) of Blitum litwinowii and bract (C), seed (D) of B. virgatum

归入球花藜属。

类球花愁与球花藜(Blitum virgatum)形态接近。 主要区别在于类球花愁通常无明显主茎, 植株匍匐, 最上面的苍片全缘, 种子卵形, 长0.8-1.2 mm; 球 花湬茎多基部分枝, 直立或斜升, 苞片具齿, 种子 球形，长1.0-1.4 mm (图3)。

\section{(4)滨藜状藜(苋科Amaranthaceae; 菉属Chenopodium)}

Chenopodium atripliciforme Murr in Magyar

Bot. Lapok 1: 360 (1902).

分布：兴都库什山脉、喜马拉雅西部的林下、 草原、河边等湿润地带, 在西藏的分布为中国新记 录。滨䔉状䓠新记录地西藏阿里噶尔县与巴基斯坦 北部、印度北部的分布同属于喜马拉雅西部, 在国 内相似生境中有该种分布。

凭证标本: 赵利清、郭柯, XZ13-081 (HIMC), 2013-9-5, 西藏阿里噶尔县扎西岗狮泉河河谷, $32^{\circ} 42^{\prime} \mathrm{N}, 79^{\circ} 27^{\prime} \mathrm{E}$ ，海拔 $4,189 \mathrm{~m}$ 。

种地理成分: 西喜马拉雅分布种。

滨藜状藜与平卧藜(Chenopodium karoi)形态接 近。主要区别在于滨藜状藜植株直立, 种子表面光 滑, 具呈辐射状沟纹; 平卧藜植株平卧, 种子表面 蜂窝状(图4)。

(5)神香草叶千屈菜(千屈菜科Lythraceae; 千屈菜 属Lythrum)

Lythrum hyssopifolia L. in Sp. Pl. 447 (1753); Chabraea hyssopifolia (L.) Bubani in Fl. Pyren. 2: 


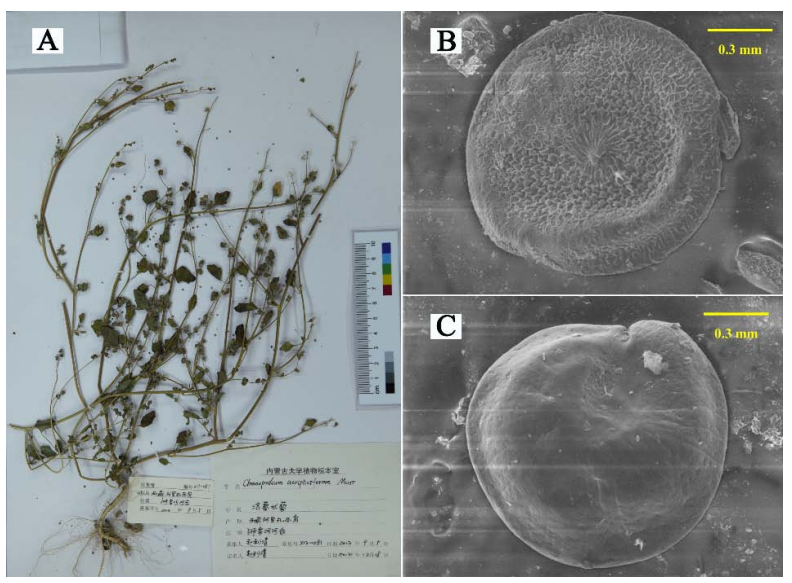

图4 滨莪状藜的标本 $(\mathrm{A})$ 、种子 $(\mathrm{C})$ 与平卧藜的种子 $(\mathrm{B})$ Fig. 4 Specimen (A), seed (C) of Chenopodium atripliciforme and seed (B) of C. karoi

542 (1899); Hyssopifolia parviflora Opiz in Seznam 53 (1852); Lythrum hyssopifolia var. cyprium Hadjik. \& Hand in Willdenowia 39: 307 (2010); Pentaglossum linifolium Forssk. in Fl. Aegypt.-Arab.: 11 (1775); Salicaria hyssopifolia (L.) Lam. in Fl. Franç. 3: 103 (1779).

分布：欧洲至中亚、北非至萨赫勒和阿拉伯半 岛的盐湿低地广泛分布, 在新疆的分布为中国新记 录。神香草叶千屈菜在新疆的分布属于该物种自然 分布的最东段, 与国外分布地哈萨克斯坦相连, 属 于古地中海分布区。

凭证标本: 赵利清、旭日、要振宇, XJ16- 8021 (HIMC), 2016-8-8, 新疆阿勒泰市北屯镇盐湿低地; 秦仁昌, 1668 (IBSC, KUN, PE), 1956-8-11, 新疆青 河, 湿润草地边缘, 海拔1,200 m。

种地理成分：古地中海分布种。

我们在中国数字植物标本馆(https://www.cvh. ac.cn/)查阅相关标本时, 发现有3份标有采自中国 新疆维吾尔自治区阿勒泰地区的该植物标本, 具体 见凭证标本中的引证, 但这些标本未被《中国植物 志》、Flora of China等收录记载。图5显示了其标 本及植株形态。

\section{(6)扁果岩苶(苶科Polygonaceae; 蓼属Polygonum)}

Polygonum cognatum subsp. chitralicum (Rech.

f. et Schiman-Czeika) Qaiser in Fl. Pakistan 205: 84-87, f. 12, A-C (2001); Polygonum chitralicum Rech. f. et Schiman-Czeika in Fl. Iranica 56: 66 (1968). 分布：兴都库什山脉的高山草地，在西藏的分

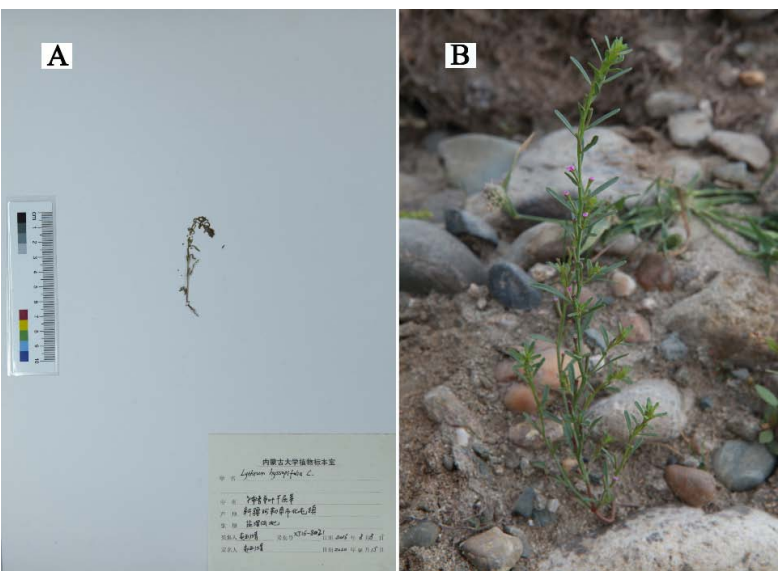

图5 神香草叶千屈菜的标本(A)和植株(B)

Fig. 5 Specimen (A) and plant (B) of Lythrum hyssopifolia

布为中国新记录。扁果岩蓼新记录地西藏札达县与 巴基斯坦北部、印度北部的分布同属于喜马拉雅西 部，在国内相似生境中有该种分布。

凭证标本: 赵利清、郭柯, XZ13-088 (HIMC), 2013-9-4, 西藏札达县底雅乡至曲松乡途中草地, $31^{\circ} 50^{\prime} \mathrm{N}, 79^{\circ} 00^{\prime} \mathrm{E}$ ，海拔 $4,373 \mathrm{~m}$ 。

种地理成分: 西喜马拉雅分布亚种。

扁果岩蓼与正种岩蓼(Polygonum cognatum)主 要区别在于其花柱2, 瘦果扁平不具明显的棱(图6); 岩苶花柱3, 瘦果卵形, 具三棱。

\section{(7)土耳其针茅(禾本科Poaceae; 针茅属Stipa)}

Stipa turkestanica Hack. in Trudy Imp. S.-Peterburgsk. Bot. Sada 26: 59 (1906).

分布：帕米尔高原、兴都库什山脉、喀喇昆仑 南部、喜马拉雅西部和厄尔布尔士山脉的草原、向 阳石质山坡，在西藏的分布为中国新记录。土耳其 针茅新记录地西藏札达县底雅乡与巴基斯坦东部、 印度北部的分布同属于喜马拉雅西部, 在国内相似 生境中有该种分布。

凭证标本：赵利清、郭柯，X13-083 (HIMC), 2013-9-9, 西藏札达县底雅乡象泉河河谷山坡, $31^{\circ} 48^{\prime} \mathrm{N}, 78^{\circ} 58^{\prime} \mathrm{E}$ ，海拔4,093 m。

种地理成分: 中亚分布种。

我们曾于中国西藏札达县底雅乡象泉河发现 土耳其针茅的变种——底雅针茅(Stipa turkestanica var. diyaensis) (Zhao \& Guo, 2017)。两者最大的区别 在于底雅针茅外稃长(11.0)12.0-13.0 mm, 芒长 17.0-20.0 cm, 芒柱被长柔毛; 而土耳其针茅外稃 长(9.5)10.8-12.1(13.5) mm, 芒长(8.8)11.8-15.8 


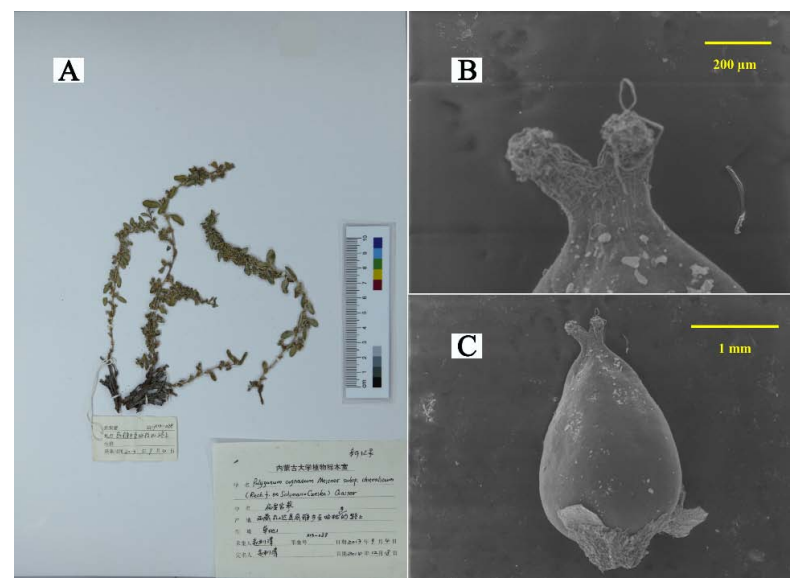

图6 扁果岩蓼的标本 $(\mathrm{A})$ 、花柱 $(\mathrm{B})$ 和瘦果 $(\mathrm{C})$

Fig. 6 Specimen (A), style (B) and achene (C) of Polygonum cognatum subsp. Chitralicum

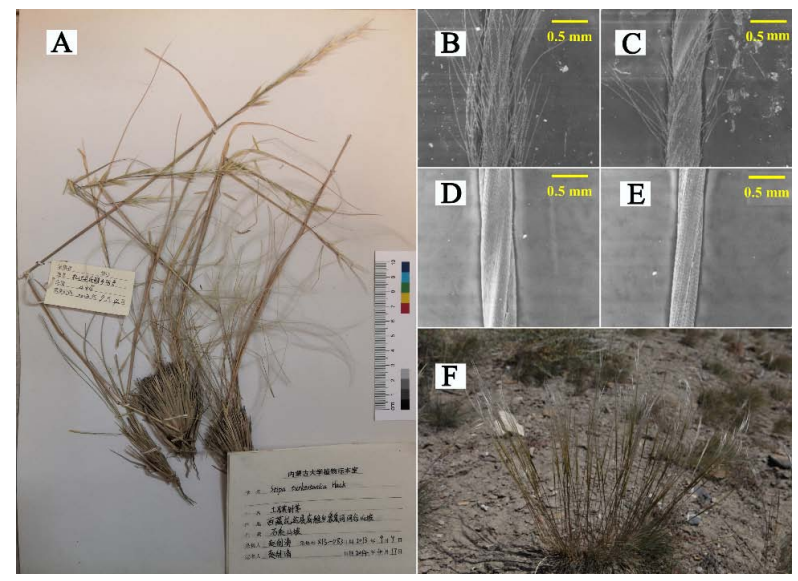

图7 土耳其针茅的标本(A)、第一芒柱(D)、第二芒柱 $(\mathrm{E})$ 、 植株(F)与底雅针茅的第一芒柱 $(\mathrm{B}) 、$ 第二芒柱 $(\mathrm{C})$

Fig. 7 Specimen (A), column of first bend (D), column of second bend (E), plant (F) of Stipa turkestanica and column of first bend (B), column of second bend (C) of S. turkestanica var. diyaensis

(18.4) cm，芒柱光滑或粗䊁(图7)。

\section{2 讨论}

本次报道的新记录物种多分布在我国西藏、新 疆与邻国接壤的边境地区。这些地区一直以来由于 交通不便等影响, 植物调查相对薄弱。随着交通条 件和野外考察设备的逐渐改善, 偏远的边境地区在 今后的区系、资源调查需要进一步加强。

本次报道新分布物种最多的为苋科植物。传统 分类系统中, 苋科与藜科是分立的。狭义苋科苞片 及花被通常为干膜质, 雄芯通常基部合生; 而莍科 苞片及花被通常为草质或肉质, 非干膜质, 雄荵通 常分离。然而, 这两个科在其他很多形态上都很相
似，是公认的近缘类群。基于 APG IV 系统(APG, 2016)，狭义苋科和䓠科合并，成为当前使用的广义 苋科。其中，愁科植物分布于欧亚大陆、南北美洲、 非洲和大洋洲的半干旱及盐碱地区，在中亚地区分 布最为广泛(朱格麟，1996)。随着青藏高原的隆起， 中亚区与青藏区分离, 西喜马拉雅地区受印度洋暖 湿气流的影响, 温和多雨, 不适宜多数藜科植物生 存，因此该地区萩科植物分布较少。这些新分布藜 科植物的发现，对于荺科植物的起源、分化和区系 研究具有重要意义。

本次报道新记录物种最多的地区为西喜马拉 雅地区，该地区在植物区系分区上一直存在着较大 的争议。对于这一问题，我们在报道该地区中国新 记录植物帕米尔四齿芥(Tetracme pamirica) 时作了 较详细的论述(朱乐和赵利清, 2019), 这些新记录植 物的发现，对于该地区植物区系的性质及区划的归 属均具有重要意义。

另外, 在巴基斯坦，采用世界自然保护联盟 (IUCN) 的红色名录标准评价扁果岩蓼为濒危 (Shabbir \& Jabeen, 2012)。在我国也仅在西藏札达县 与邻国接壤的边境地区有少量分布, 因此, 掌握其 分布对该分类群的保护至关重要。同时，有研究表 明，绵羊、牛等家畜食用神香草叶千屈菜会中毒 (Lancaster et al, 2009; Tran et al, 2013), 故掌握该物 种的详细分布情况, 科学有效地防止其在草场中的 爆发性增长, 对畜牧业生产、经营也有重要意义。

\section{ORCID}

扈凡斌 (1D) https://orcid.org/0000-0002-4203-0916

\section{参考文献}

APG (The Angiosperm Phylogeny Group), Chase MW, Christenhusz MJM, Fay MF, Byng JW, Judd WS, Soltis DE, Mabberley DJ, Sennikov AN, Soltis PS, Stevens PF (2016) An update of the Angiosperm Phylogeny Group classification for the orders and families of flowering plants: APG IV. Botanical Journal of the Linnean Society, 181, $1-20$.

Chai W, Yan P (2010) Astragalus beitashanensis, a new species of Leguminosae from Xinjiang, China. Novon, 20(1), 21-22.

Du C, Liao S, Boufford DE, Ma JS (2020) Twenty years of Chinese vascular plant novelties, 2000 through 2019. Plant Diversity, 42, 393-398.

Editorial Committee of Flora of Xinjiang (2011) Flora of Xinjiang, Vol. 3. Xinjiang Science \& Technology Press, 
Urumqi. (in Chinese) [新疆植物志编辑委员会 (2011) 新 疆植物志 (第三卷). 新疆科学技术出版社, 乌鲁木齐.]

Fuentes-Bazan S, Uotila P, Borsch T (2012) A novel phylogeny-based generic classification for Chenopodium sensu lato, and a tribal rearrangement of Chenopodioideae (Chenopodiaceae). Willdenowia, 42, 5-24.

Fu KJ, He YQ, He SB (1993) Flora Reipublicae Popularis Sinicae, Vol. 42(1), pp. 78-349. Science Press, Beijing. (in Chinese) [傅坤俊, 何业祺, 何善宝 (1993) 中国植物志 (第四十二卷第一分册). 科学出版社, 北京.]

Grubov VI (2001) Key to the Vascular Plants of Mongolia. Science Publishers Inc., Enfield.

Grubov VI (2007) Plants of Central Asia, Vol. 2. Oxford \& IBH Publishing Co. Pvt. Ltd., New Hampshire.

Grubov VI, Ulzijchutag N (2004) Plants of Central Asia: Plant Collections from China and Mongolia, Vol. 8. Science Publishers Inc., Enfield.

Kong XW, Zhu GL (1979) Flora Reipublicae Popularis Sinicae, Vol. 25(2), pp. 28-98. Science Press, Beijing. (in Chinese) [孔宪武, 朱格麟 (1979) 中国植物志 (第二十五 卷第二分册). 科学出版社, 北京.]

Lancaster MJ, Nimmo JS, Lenghaus C, Gill IJ, Crawford RD, Badman RT, Samuel JL, Werner CJ, Button C, Kvalheim N (2009) Lythrum hyssopifolia (lesser loosestrife) poisoning of sheep in Victoria. Australian Veterinary Journal, 87, 476-479.

Li AR (1998) Flora Reipublicae Popularis Sinicae, Vol. 25(1). Science Press, Beijing. (in Chinese) [李安仁 (1998) 中国 植物志 (第二十五卷第一分册). 科学出版社, 北京.]

Li AR, Bao BJ (2003) Polygonum L. In: Flora of China, Vol. 5 (eds Wu ZY, Peter HR, Hong DY), pp. 278-315. Science Press, Beijing \& Missouri Botanical Garden Press, St. Louis.

Li SG, Liu LF (1983) Flora Reipublicae Popularis Sinicae, Vol. 52(2). Science Press, Beijing. (in Chinese) [李树刚, 刘兰芳 (1983) 中国植物志(第五十二卷第二分册). 科学出版社, 北京.]

Nasir E, Ali SI (1979) Flora of Pakistan. Missouri Botanical Garden Press, St. Louis.

Qin HN (2007) Lythrum L. In: Flora of China, Vol. 13 (eds Wu ZY, Peter HR, Hong DY), pp. 281-282. Science Press, Beijing \& Missouri Botanical Garden Press, St. Louis.

Sang WG, Ma KP, Axmacher JC (2011) Securing a future for China's wild plant resources. BioScience, 61, 720-725.

Shabbir R, Jabeen A (2012) Contribution to the red list of plants of Pakistan: A review. Journal of Biodiversity and Environmental Sciences, 2, 14-25.

Sukhorukov AP, Kushunina M (2015) Taxonomic revision of Chenopodiaceae in Nepal. Phytotaxa, 226, 288-291.
Sukhorukov AP, Liu PL, Kushunina M (2019) Taxonomic revision of Chenopodiaceae in Himalaya and Tibet. PhytoKeys, 116, 27301.

Sun YH, Guo BZ (1987) Flora Reipublicae Popularis Sinicae, vol. 9(3), pp. 268-287. Science Press, Beijing. (in Chinese) [孙永华, 郭本兆 (1987) 中国植物志(第九卷第三分册), 268-287页. 科学出版社, 北京.]

Tran JN, Yang PJ, Morton AG, Todd AA, Boulton JG, Philbey AW (2013) Suspected Lythrum hyssopifolia (lesser loosestrife) poisoning of cattle. Australian Veterinary Journal, 91, 474-476.

Wu ZL (2006) Stipa L. In: Flora of China, Vol. 22 (eds Wu ZY, Peter HR, Hong DY), pp. 196-203. Science Press, Beijing \& Missouri Botanical Garden Press, St. Louis.

Wu ZY (1983) Flora of Tibet, Vol. 1. Science Press, Beijing. (in Chinese) [吴征镒 (1983) 西藏植物志(第一卷). 科学 出版社, 北京.]

Wu ZY (1987) Flora of Tibet, Vol. 5. Science Press, Beijing. (in Chinese) [吴征镒 (1987) 西藏植物志(第五卷). 科学 出版社, 北京.]

Wu ZY, Peter HR, Hong DY (2013) Flora of China, Vol. 1, p. 21. Science Press, Beijing \& Missouri Botanical Garden Press, St. Louis.

Xu LR (2010) Astragalus L. In: Flora of China, Vol. 10 (eds Wu ZY, Peter HR, Hong DY), pp. 328-453. Science Press, Beijing \& Missouri Botanical Garden Press, St. Louis.

Zhao LQ, Guo K (2017) A new species and a new variety of Stipa (Poaceae) from Tibet, China. Annales Botanici Fennici, 54, 49-53.

Zhu GL (1996) Origin, differentiation, and geographic distribution of the Chenopodiaceae, 34, 486-504. (in Chinese with English abstract) [朱格麟 (1996) 藜科植物 的起源、分化和地理分布. 植物分类学报, 34, 486-504.]

Zhu GL (2003a) Chenopodium L. In: Flora of China, Vol. 5 (eds Wu ZY, Peter HR, Hong DY), pp. 378-383. Science Press, Beijing \& Missouri Botanical Garden Press, St. Louis.

Zhu GL (2003b) Atriplex L. In: Flora of China, Vol. 5 (eds Wu ZY, Peter HR, Hong DY), pp. 360-366. Science Press, Beijing \& Missouri Botanical Garden Press, St. Louis.

Zhu L, Zhao LQ (2019) Tetracme pamirica Vassilcz., a newly recorded species of the genus Tetracme from China. Acta Botanica Boreali-Occidentalia Sinica, 39, 1506-1508. (in Chinese with English abstract) [朱乐, 赵利清 (2019) 中国 四齿芥属一新记录种——帕米尔四齿芥. 西北植物学报, 39, 1506-1508.]

(责任编委: 陈又生 责任编辑: 黄祥忠)

\section{附录 Supplementary Material}

附录16个中国新纪录种和1个中国新纪录亚种形态描述

Appendix 1 Diagnosis of six newly recorded species and one newly recorded subspecies from China http://www.biodiversity-science.net/fileup/PDF/2021181-1.pdf 
扈凡斌, 辛玥, 郭柯, 赵利清 (2021) 采自西藏和新疆的 7 种中国新记录植物. 生物多样性, 29, 1265-1270. http://www.biodiversity-science.net/CN/10.17520/biods.2021181

\section{附录1 6 个中国新纪录种和1个中国新纪录亚种形态描述}

2 Appendix 1 Diagnosis of six newly recorded species and one newly recorded subspecies from China

\section{A 宝格达黄芪 Astragalus baitagensis}

多年生草本, 茎上升或直立, 有细棱, 被白色短毛, 上部较密并混有黑色毛。单数羽状复叶, 长2-6 cm, 小 叶7(9)-13(15)枚, 托叶分离, 三角形, 长1-2 mm, 密被白色, 混有黑色毛; 小叶圆状倒卵形、矩圆形或矩圆状倒 卵形, 长2-12 mm, 宽2-7 mm, 先端钝圆或微凹, 基部圆形或宽楔形, 上面疏被白色单毛或近无毛, 下面密被 白色单毛。总状花序具12-18小花, 排列较稀疏, 花序轴5-10 cm; 花小, 苞片锥形或披针状线形, 长约1-3(4) $\mathrm{mm}$, 被短黑毛, 常混生短白毛; 花梗1-1.5 mm; 花募钟形, 长约2.5-3(4) mm, 密被黑毛, 䓫齿三角形, 约为莒 筒的1/6; 花冠淡紫色或淡粉红色, 5-7 mm, 旗瓣倒卵形, 长约 $8 \mathrm{~mm}$, 宽约 $4 \mathrm{~mm}$, 先端微缺, 中部以下渐狭, 瓣 柄不明显。荚果长(5)6-8 mm，宽3-4 mm，钝三角状卵形或三角状长圆形。花果期7-8月。

\section{B 灰滨藜 Atriplex pallida}

一年生草本, 高15-50 cm。茎直立或外倾, 光滑, 苍白色, 通常多分枝。叶片宽卵形、三角状卵形至宽披 针形, 长2-7 cm, 宽1-4 cm, 全缘或有少量圆齿, 先端急尖或短渐尖并有短尖头, 基部宽楔形至楔形, 绿色, 有 时两面均有粉而近于同色; 叶柄长 $1.5 \mathrm{~cm}$ 以上。花簇生于叶腋, 并于茎和枝的上部集成间断的穗状花序, 花序 轴有密粉; 雄花花被5; 雌花的苍片果时菱形至矩圆状卵形, 被粉, 全缘或有齿, 下部的边缘合生, 靠基部的中 心部黄白色, 具浮凸脉, 缘部有绿色网脉, 具短柄。胞果扁, 近圆形; 果皮白色, 膜质, 与种子贴伏。种子直立, 直径1.5 mm, 黄褐色至黑色。花果期7-9月。

\section{C 类球花藜 Blitum litwinowii}

一年生草本, 高2-10 cm。茎多由基部分枝, 分枝长到 $50 \mathrm{~cm}$, 次生分枝很少, 无明显主茎, 匍匐, 老时淡黄 色，嫩时浅绿色，具条纹。基生叶的叶片三角形至三角状卵形，长 $2-4 \mathrm{~cm}$, 宽1-2 cm, 两面均为鲜绿色, 无粉或 稍有粉, 先端渐尖, 基部楔形、截形或戟形, 边缘具不整齐的牙齿, 近基部的牙齿稍下弯, 叶柄长是叶片2-5倍; 茎生叶逐渐变小, 披针形或卵状戟形, 全缘或稀具齿, 小裂片和齿多数反折。花两性兼雌性, 密生于腋生短枝 上形成球状或桑甚状团伞花序; 花被3, 浅绿色, 果熟后变为多汁并呈红色。胞果扁卵球形, 果皮膜质透明, 与 种子贴生。种子直立, 约 0.8-1.2 mm, 红褐色至黑色, 边缘针或截形, 有光泽, 多数不开槽; 胚半环形。花期 67月，果期8-9月。

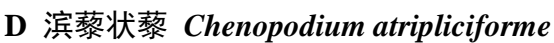

一年生草本, 高达70(120) cm。茎直立, 多分枝, 圆柱状或有针棱, 具绿色色条, 有时带红色。叶片卵形至 宽卵形, 通常三浅裂, 长1.5-3 cm, 宽1-2.5 cm, 浅绿色, 无粉或稍有粉, 基部截形或宽楔形; 中裂片全缘或具 圆齿, 先端钝渐尖或急尖并有短尖头; 侧裂片位于叶片中部或稍下, 钝而全缘或具齿; 叶柄有时长于叶片或等 长, 细瘦; 茎上部叶卵形, 全缘。花数个簇生或稀单生, 再于小分枝上排列成短于叶的腋生圆雉状花序; 花被 裂片5或 4 , 卵形, 先端钝, 背面微具纵隆脊, 边缘膜质并带黄色, 果时部分合生。果皮膜质, 黄褐色, 与种子贴 生。种子横生, 双凸镜状, 直径(1.0)1.2-1.4 mm, 黑色, 种皮几乎平滑, 表面具放射状纹。花果期8-9月。

\section{E 神香草叶千屈菜 Lythrum hyssopifolia}

一年生草本, 高3-40 cm。茎直立, 单生或具分枝。叶对生或互生, 线形、披针形至卵圆形, 长10-25 mm, 宽2-8 mm, 全缘。花单生叶腋处; 花辐射对称, 4-6基数; 募筒花期圆雉形, 果期圆筒形, 长4-6 mm, 裂片4-6, 附属体1-1.5 mm, 钻形, 约长于萝裂片的两倍; 花瓣4-6, 粉红色或淡紫色, 矩圆形或栯圆形, 基部楔形, 长2-

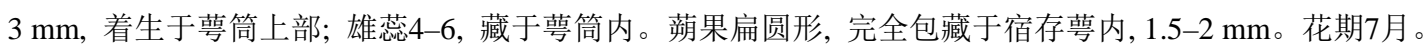

\section{F 扁果岩蓼 Polygonum cognatum subsp. chitralicum}

多年生草本。根粗壮, 木质化, 直径可达 $1.5 \mathrm{~cm}$ 。茎平卧, 自基部多分枝, 高8-15 cm, 具纵棱, 沿棱具小突 起。叶椭圆形, 长1-2 cm, 宽5-13 mm, 顶端稍尖或圆钝, 基部狭楔形, 边缘全缘, 两面无毛, 下面中脉微突出, 侧脉不明显; 叶柄长 $2-5 \mathrm{~mm}$, 基部具关节; 托叶鞘薄膜质, 白色, 透明, 具褐色脉, 顶端 2 至数裂。花几遍生于 植株, 1-5朵, 生于叶腋; 苞片膜质, 顶端渐尖; 花梗长1-3 mm; 花被5裂, 开裂至中部, 花被片卵形, 绿色, 边 
扈凡斌，辛玥，郭柯，赵利清 (2021) 采自西藏和新疆的 7 种中国新记录植物. 生物多样性, 29, 1265-1270. http://www.biodiversity-science.net/CN/10.17520/biods.2021181

缘淡红色或白色, 长1.5-2 mm; 雄荵8, 比花被短, 花丝基部扩展; 花柱2, 柱头头状。瘦果扁平, 卵形, 长2.5-3 $44 \mathrm{~mm}$, 黑色, 有光泽, 包于宿存花被内。花期6-8月, 果期7-9月。

\section{G 土耳其针茅 Stipa turkestanica}

46

多年生草本, 高40-60 cm, 密丛生, 秆斜升或直立, 具2-4节; 基生叶长为秆的 $2 / 3-3 / 4$, 叶鞘短于节, 粗粘 或被短柔毛; 叶片纵卷成针状, 外面被小刺毛, 叶舌膜质, 狭披针形, 长(2.6)4.5-8.2(11.5) mm, 先端芒状; 圆

48 锥花序裸露, 不被叶鞘包裹, 长约8-14 cm, 分枝较短, 着生1-2枚小穗; 颖尖披针形, 边缘膜质透明, 线段延伸 成丝状, 长(2.5)3.4-4.1(5.1) cm, 第二颖稍短于第一颖, 具5-9脉; 外稃长(9.5)10.8-12.1(13.5) mm, 背部具排列

50 成纵行的短毛, 顶端关节处光滑, 基盘锐尖, 长约 $2.5 \mathrm{~mm}$, 密生细柔毛; 内稃与外稃近等长, 背部略具纵列短 柔毛, 不达顶部; 芒长(8.8)11.8-15.8(18.4) cm, 二回膝曲, 第一芒柱长2.2-3 cm, 扭转, 第二芒柱长1-2 cm, 芒 柱整体粗粘或光滑, 芒针长9-13 cm, 被长约 $5 \mathrm{~mm}$ 的柔毛。花果期7-9月。 